\title{
El dominio público y privado de las aguas del río Tunuyán: Litigios a finales del siglo XIX en Mendoza (Argentina)*
}

\section{Resumen}

El presente trabajo explora sobre la injerencia gubernamental, a través de la regulación de las aguas del río Tunuyán a fines del siglo XIX y cómo fue moldeando uno de los tres oasis más importantes de Mendoza. La investigación historiza y problematiza sobre los litigios de aguas que sentaron bases para la jurisprudencia en torno al manejo, control y apropiación del recurso. En los casos analizados queda manifiesto la importancia de reconstruir los contextos históricos y sociales de los litigantes. De esta manera, proponemos generar un marco explicativo más amplio de los procesos de apropiación de recursos por parte de las élites locales. Para ello nos valemos tanto del análisis documental como de la cartografía oficial histórica. Se concluye que, si bien dichos litigios se presentaron como una discusión sobre el dominio público y privado de las aguas, propendieron a incrementar la institucionalización y el dominio estatal de esas aguas favoreciendo a las élites locales que formaban parte del poder político.

\section{Palabras Clave}

Tesauro: Río Tunuyán, dominio público y privados de las aguas, litigios sobre el agua.

Referencia bibliográfica para citar este artículo: Fili, Juan Pablo y Ayelén Engelman, Anabella. "El dominio público y privado de las aguas del río Tunuyán: Litigios a finales del siglo XIX en Mendoza (Argentina)". Anuario de Historia Regional y de las Fronteras, 25.1 (2019): 47-68

Fecha de recepción: 30/07/2019

Fecha de aceptación: 15/10/2019

Juan Pablo Fili: Licenciado en Sociología (Universidad Nacional de Cuyo). Becario doctoral del Consejo Nacional de Investigaciones Científicas y Técnicas con sede en el Departamento de Geografía de la Facultad de Filosofía y Letras, Universidad Nacional de Cuyo. Candidato a doctor en Estudios Sociales Agrarios (Centro de Estudios Avanzados, Universidad Nacional de Córdoba), Argentina. Código ORCID: 0000-0001-7672-3772 Correo electrónico: inst-geo@ffyl.uncu.edu.ar

Anabella Ayelén Engelman: Geógrafa Profesional (Universidad Nacional de Cuyo). Becaria doctoral del Consejo Nacional de Investigaciones Científicas y Técnicas con sede en el Instituto de Ciencias Humanas, Sociales y Ambientales. Candidata a doctora en Ciencias Sociales (Facultad de Ciencias Políticas y Sociales, Universidad Nacional de Cuyo), Argentina. Código ORCID: 0000-0001-7672-3772 Correo electrónico: aengelman@mendoza-conicet.gob.ar

\footnotetext{
* Este texto ha sido financiado por CONICET y PICTO UNCuyo 0012-2016.
} 


\title{
The public and private domain of the waters of the Tunuyán River: Litigation at the end of the 19th century in Mendoza (Argentina)
}

\begin{abstract}
The present work analyses the government interference, by means of the regulation of the waters of the Tunuyán River at the end of the nineteenth century and how it was shaped one of the three most important oases in Mendoza. The historical and problematic research on water litigation that laid the foundation for jurisprudence regarding the management, control and appropriation of the resource. In the analyzed cases, it is evident the importance of reconstructing the historical and social contexts of the litigants. In this way, it is proposed to generate a broader explanatory framework of the processes of appropriation of resources by local elites. For this we use both the document analysis and the official historical cartography. It is concluded that, although these litigations were presented as a discussion on the public and private domain of the waters, they tended to increase the institutionalization and state dominance of those waters, favoring the local elites which were part of the political power.
\end{abstract}

Keywords

Tesauro: Tunuyán River, public and private domain of water, water litigation.

\section{Domínio público e privado das águas do rio Tunuyán: litígios no final do século XIX em Mendoza (Argentina)}

\section{Resumo}

Este artigo explora a interferência do governo, através da regulação das águas do rio Tunuyán no final do século 19 e como estava moldando um dos três oásis mais importantes em Mendoza. A pesquisa histórica e problemática sobre litígios da água que lançou as bases para a jurisprudência em relação à gestão, controle e apropriação do recurso. Nos casos analisados, é evidente a importância de reconstruir os contextos histórico e social dos litigantes. Dessa forma, propõe-se gerar uma estrutura explicativa mais ampla dos processos de apropriação de recursos pelas elites locais. Para isso, usamos tanto a análise documental quanto a cartografia histórica oficial. Conclui-se que, embora esses litígios foram apresentados como uma discussão sobre o domínio público e privado das águas, eles tendem a aumentar a institucionalização e o domínio estatal dessas águas, favorecendo as elites locais que faziam parte do poder politico.

\section{Palavras chave}

Tesauro: rio Tunuyán, domínio público e privado da água, litígios sobre a água. 


\section{Introducción}

Sobre el río Tunuyán se ha desarrollado uno de los tres oasis productivos más importantes de la provincia de Mendoza. Sus orígenes se remontan al siglo XVII bajo la designación de la región como Curato de Uco, con fines evangelizadores hacia las comunidades originarias. Previo a la incorporación de estos territorios al Virreinato del Río de la Plata, la zona ya gozaba de fama por ser la segunda más importante concentración poblacional. Esto quizás explica la denominación que le valió por parte de los historiadores locales como la región de las estancias, ya que concentraba las más prestigiosas que se hallaban desde la época colonial. ${ }^{1}$ Las tierras surcadas por las aguas del río Tunuyán eran requeridas con tales fines, por ello fue relevante y necesaria la regulación de las aguas de este río desde aquellos albores.

No obstante, recién a fines del siglo XIX se crea el Departamento General de Aguas (1895) mediante la sanción de la Constitución provincial por parte de la elite gobernante. Pretendían ordenar una situación hídrica imperante que en sus relatos se tornaba insostenible. De esta manera, comienza una creciente injerencia gubernamental en términos legales y pragmáticos en pos de consolidar institucionalmente la gestión del agua en la provincia de Mendoza. Vale destacar que, si bien existía la figura de Juzgado de Aguas, en la práctica muchas veces prevalecían las iniciativas de privados.

Diferentes estudios desde la geografía, la historia social y regional abordaron extensamente este proceso, como así también aquellos que han analizado los impactos sociales y territoriales en torno al manejo estatal de los ríos mendocinos y las tensiones derivadas de ello. ${ }^{2}$ Sin embargo, poco se sabe sobre los mecanismos y argumentos que utilizaban las diversas partes en un litigio de aguas y la relación de estos litigios con un cambio de paradigma productivo y social. Tampoco se conoce en profundidad las características sociales de los reclamantes de derecho de agua en momentos previos a la creación del Departamento de Aguas (actual Departamento General de Irrigación). Las respuestas a estos interrogantes iluminan estrategias de grupos de la sociedad que están ancladas en proceso más amplios.

En este sentido, la capitalización de sectores de la burguesía chilena y las estrategias de "interiorización"” de la elite de gobierno intervino en la jurisprudencia

\footnotetext{
${ }^{1}$ Pedro Martínez, Historia de Mendoza (Vol. 7). Plus Ultra; Jorge Scalvini, Historia de Mendoza ” Mendoza: Ed. Spadoni (1965): 335

${ }^{2}$ Laura María Torres, et al. “Acceso a los recursos y distribución de la población en tierras secas de Argentina: el caso de Mendoza. Aportes hacia la equidad territorial.” Scripta Nova: revista electrónica de geografia y ciencias sociales 7 (2003); Montaña, Elma. "Identidad regional y construcción del territorio en Mendoza (Argentina): memorias y olvidos estratégicos." Bulletin de l'Institut français d'études andines 36 (2) (2007): 277-297; Montaña, Elma. "Las disputas territoriales de una sociedad hidráulica. Conflictos en torno al agua en Mendoza, Argentina" REVIBEC-FLACSO, (2008); Martín, Facundo. Las transformaciones recientes en la agricultura de oasis en Mendoza, Argentina. Una aproximación al caso de la reestructuración vitivinícola desde la economía política de la agricultura. MS thesis. Buenos Aires: FLACSO. Sede Académica Argentina, 2009; Ivars, Jorge Daniel. "Mercados mundiales y racionalización del uso del agua en Mendoza (Argentina)." Ánfora 22.39 (2015): 71-97.

${ }^{3}$ Como alude Jorba (1998) entendemos la interiorización de las elites locales como las estrategias y
} 
de aguas a nivel local. Profundizar en este proceso implica repensar los litigios sobre aguas asociados a estrategias locales y globales de diferentes sujetos históricos. ${ }^{4}$ Así, al acudir a una explicación donde intervienen diferentes procesos, el sujeto se vuelve un catalizador de las concepciones y pensamientos de la época. Cuestión que ha sido poco tematizada en los estudios preocupados por la historia del agua y su relato social.

Al respecto, fundamentamos la importancia de los litigios seleccionados en una recurrencia de estos en la bibliografía histórica consultada, pero que poco ahondaron en su complejidad. Así Scalvini destaca:

Un ruidoso litigio se inicia en este mes de junio, a raíz de la solicitud del ciudadano chileno Pastor Ovalle, que pide "se le autorice a utilizar el agua del Río Tunuyán, para cultivar mil seis-cientas hectáreas de terreno de su propiedad, de acuerdo con una antigua concesión”. El Ejecutivo se negó, por no autorizar la ley vigente "más derechos de agua, que los correspondientes a terrenos en actual cultivo. ${ }^{5}$

Indagaremos en el caso Ovalle como un condensador que sirvió para sentar precedentes legales ante eventos conflictivos posteriores en lo que respecta al dominio jurídico ${ }^{6}$ de las aguas. Por ello, el objetivo de la investigación giró en torno a la contextualización y el análisis de los documentos históricos. Posteriormente realizamos una reflexión sobre el proceso de transición que operó a finales del siglo XIX y principios del siglo XX en cuanto a la gestión y el manejo del agua teniendo en cuenta las características sociales, políticas y económicas de la región.

El caso Ovalle junto con el tratamiento de otros dos conflictos que tuvieron lugar entre privados en la misma cuenca, nos permitió la representación de una época en la que el Estado provincial comenzó a tener mayor participación en el manejo de las aguas.

Como se observa en el Mapa $\mathrm{N}^{\circ} 1$ los litigios sobre los que ahondaremos se desarrollaron sobre el curso medio del río Tunuyán. El río se desliza en sentido sur-norte en pendiente decreciente sobre su propio cono de deyección o tambien denominada planicie aluvional del piedemonte, donde su lecho mayor está limitado por barrancas de escasas alturas. Al este de las planicies aluvionales, se presentan depósitos eólicos y sedimentos de origen palustre y lacustre; siendo sobre estos suelos y gracias a las aptitudes que poseen que se ha desarrollo la próspera actividad agrícola. ${ }^{7}$

procesos desplegados para federalizar el poder de las entonces Provincias Unidas del Río de la Plata y así afinazar los territorios del oeste argentino desligándolos de la influencia chilena.

${ }^{4}$ Siguiendo a Tompson (1989) entendemos al sujeto histórico como la expresión política de una clase que abarca prácticas nociones compartidas que forman una identidad social.

${ }^{5}$ Jorge Scalvini, Historia de Mendoza Mendoza: Ed. Spadoni (1965): 335

${ }^{6}$ Entendemos al dominio jurídico como una relación de derecho entre el dueño y la cosa de su propiedad. En el caso que aquí presentamos lo que se encuentra en litigio es la definición de quién es el dueño (público o privado) y de la cosa objeto de propiedad (el agua o el beneficio de usufructo de las aguas).

${ }^{7}$ Rosier Barrera, “Hidrología del río Tunuyán”, Boletín de Estudios Geográficos 36 (1962). 
Mapa $\mathrm{N}^{\circ} 1^{8}$ Localización de las estancias en litigio seleccionadas

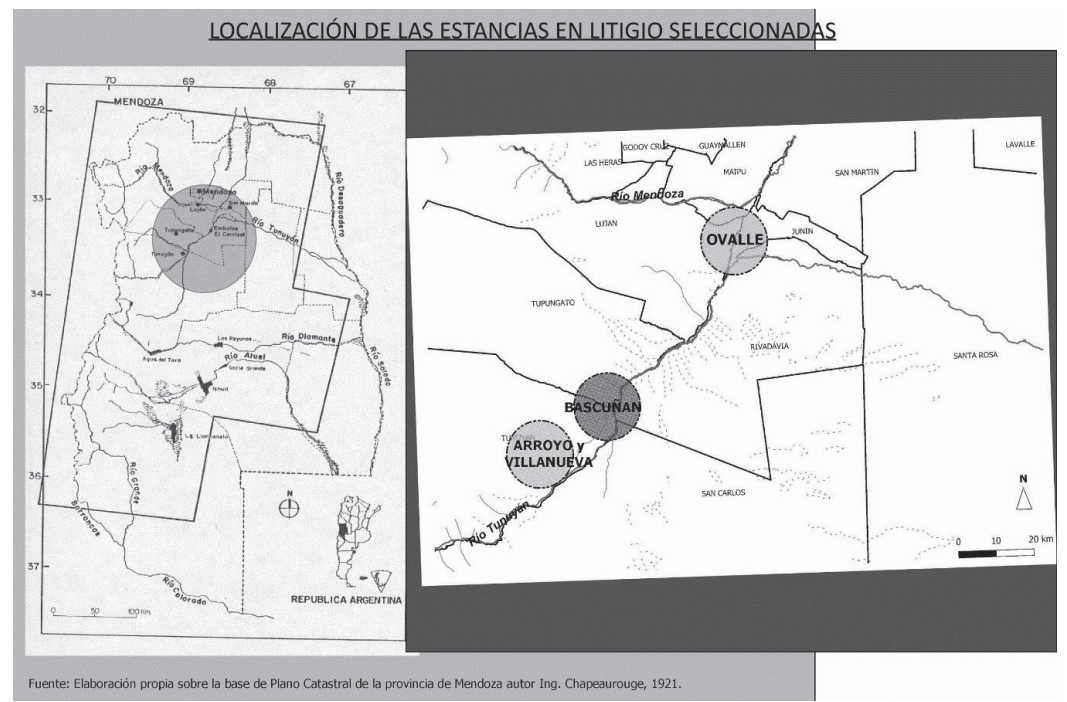

Así las cosas, podríamos sintetizar los principales puntos que trataremos en la presente investigación de la siguiente manera:

- Los litigios tratados en este trabajo transcurren durante un período de consolidación estatal-institucional en la gestión del agua,

- La consolidación de autoridades del agua avaladas por las instituciones nacionales reforzó el carácter estatal de las aguas,

- Esta etapa de construcción estatal-nacional coincide con una etapa de desacople de la economía provincial mendocina respecto de la chilena,

- Esta complejidad creciente en la gestión permitió un manejo discrecional de las aguas,

La metodología consistió en el análisis crítico de bibliografía histórica, fuentes documentales, legislativas y cartográfica. En virtud de ello se procedió al análisis intensivo y la triangulación de documentos procedentes del Archivo Histórico del Agua de la provincia de Mendoza. El archivo fue creado recientemente y está en proceso de valoración, catalogación y digitalización. La presente investigación deriva de dicho proceso.

\section{Los antecedentes institucionales y jurídicos en torno al dominio público de las aguas en Mendoza}

Hasta 1776 los actuales territorios de las provincias de Mendoza, San Luis y San Juan constituyeron la Región de Cuyo, una de las doce provincias que pertenecían al dominio de la Capitanía General de Chile. La nueva jurisdicción quedó, a partir de

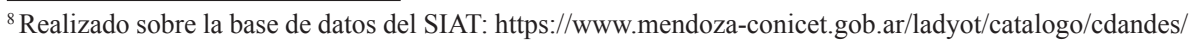
pa412.htm. 
esa fecha, bajo la esfera de influencia del recientemente creado Virreinato del Río de la Plata, cuyo centro gravitacional giraba en torno a Buenos Aires. ${ }^{9}$ Previo a dicho acontecimiento, la organización territorial que prevalecía se caracterizaba por la unión de las ciudades cabeceras de estos territorios con Chile, a través de rutas comerciales que coincidían con corredores a la rivera de los principales ríos Mendoza y Tunuyán. ${ }^{10}$ Por otra parte, en vistas a superar los obstáculos que representaban las condiciones de aridez para el desarrollo económico, ya desde el siglo XVI se habían registrado diferentes intervenciones por parte de la Corona Española en cuestiones relacionadas al riego. Como por ejemplo la regulación y cuidado de los cauces (Acta Capitular del año 1566), la creación de la figura del Alcalde de Aguas (1606) y se insistió en legislación en materia de limpieza de canales y acequias (1605-1609). ${ }^{11}$

Ya en el siglo XIX, precisamente en 1833 el gobernador Don Pedro Molina crea el Juzgado de Aguas y diez años después su sucesor el Fraile Aldao presenta el Primer Reglamento para éste. Además, cabe hacer referencia a otros antecedentes como las Leyes de Agua de los años 1871 y 1872, pocas veces mencionadas en la bibliografía, pero presentes en los expedientes de la época y en el libro de Antonio Bermejo "Legislación y Jurisprudencia" que data de 1885. Por lo declarado en aquellos documentos las Leyes de Agua en esta etapa buscaban que los poseedores dominiales declararan el uso del agua, aunque no se expresaban sanciones a quienes no lo hicieran. Simultáneamente, se prohibía aumentar la cantidad de agua y la extensión de canales mientras que al mismo tiempo se derogaba las concesiones que no se hubieran aprovechado.

Con todo, es recién a partir de la sanción de la Ley de Aguas en 1884 que se puede considerar una regulación estricta del riego, y a partir de esto la constitución de una auténtica policía de las aguas. Según Marzo e Inschauspe ${ }^{12}$ es hasta 1888 que se puede dar por completa la legislación ya que gracias a la Ley Complementaria de Aguas se terminó de configurar la Ley General de Aguas de ese año, la cual instrumentó la creación del Departamento General de Agua. ${ }^{13}$ Probablemente los conflictos entre las partes privadas y entre privadas-pública durante los 4 años que separan a una ley de la otra fue lo que generó la necesidad de ajustar y complementar la legislación.

El caso Ovalle se desarrolló en el interregno de estas leyes, por lo que marcó un hito en la autonomía de las autoridades del agua y la ley que los protegía. Es probable también, que el caso Ovalle haya consolidado ajustes en la jurisprudencia de la ley complementaria. Dos cuestiones refuerzan esta idea, la primera es la edición del

\footnotetext{
${ }_{9}^{9}$ Segheso de Lopez, M, El proceso constituyente mendocino en Mendoza, Cultura y Economía, (2004).

${ }^{10}$ Recientes trabajos (Ots, Cahiza y Gascón, 2015) dan cuenta de una conexión entre las cuencas alta y baja del Tunuyán como consecuencia de su carácter de corredor y por motivo de las prácticas sociales de intercambio de bienes vinculadas a la subsistencia.

${ }^{11}$ http://www.historiademendoza.com.ar/noticias_historicas.php?id=8; Ponte, J. R. (2006). Historia del regadío: las acequias de Mendoza, Argentina.

${ }^{12}$ Miguel Marzo y Osvaldo Inchauspe, Geografia de Mendoza, 1967.

13 El entonces gobernador de la provincia, Rufino Ortega, designa a Laureano Galigniana como Superintendente, autoridad máxima del Departamento General de Agua.
} 
libro de Antonio Bermejo sobre el caso Ovalle ${ }^{14}$ que, como mencionamos, comienza con la leyenda "Legislación y Jurisprudencia", documento de circulación interna de la Inspección General de Irrigación, lo cual marca la relevancia del caso en cuestión. La segunda tiene que ver con las palabras que expresa Antonio Bermejo al ministro de gobierno de Mendoza cuando remite la sentencia dictada por la Corte Federal. En ellas señala que:

[...] las doctrinas sostenidas por ese Gobierno, sobre aprovechamiento de aguas y las leyes sobre la materia dictadas por la Legislatura de Mendoza, han merecido autorizada consagración de parte de la Suprema Corte Nacional de Justicia formándose así una jurisprudencia que evitará las reclamaciones análogas que en los sucesivo hubieran podido promoverse. ${ }^{15}$

\section{El conflicto entre el derecho público (estatal) y privado de las aguas del Río Tunuyán: El Caso Ovalle}

Hacia 1854, los hermanos Pastor y Matías Ovalle compraron a Adolfo Maza $^{16}$ una estancia-campo que incluía 100 cabezas de ganado ovino, herramientas y derecho de riego. Además, contaban con la venia del entonces Juez de Aguas para abrir una boca toma y así regar 400 cuadras de terreno. ${ }^{17}$ Como podemos observar en la imagen satelital (Fig. $\mathrm{N}^{\circ} 2$ ) el terreno comprado por los hermanos se localizaba en el entonces denominado Partido de Barrancas específicamente al este de los actuales Cerrillos de Lunlunta entre los ríos Mendoza y Tunuyán. Durante los primeros años las tierras tuvieron muy poca producción, por ello cuando se realizó un padrón de tierras cultivadas en el año 1873, solo tenía plantadas 5 cuadras. Aunque la ley de 1871 prohibía continuar cultivando durante el lapso 1873-1884, los hermanos pusieron en funcionamiento entre 40 y 50 hectáreas más. Finalmente, la ley de Aguas de 1884 les reconoció el derecho de esas tierras cultivadas.

El Mapa $\mathrm{N}^{\circ} 2$ es una imagen satelital actual en la cual puede observarse que las tierras adquiridas por los hermanos Ovalle se encontraban al sur del río Mendoza, sobre la cuenca media del Río Tunuyán.

Diferentes historiadores coinciden en señalar la década de 1880 como el inicio de la decadencia de los intercambios comerciales con Chile, y por lo tanto del modelo ganadero exportador. La llegada del ferrocarril propició mayor interacción entre la provincia y el resto del país, mientras que el auge de la actividad ganadera en la región pampeana comenzó a desplazar la producción mendocina. Dado que, recién en 1885 los hermanos Ovalle comienzan el litigio con el Gobierno de Mendoza para proveer de agua a 1500 hectáreas de tierra de sus propiedades, es lícito suponer que podían optar por diferentes estrategias. Por un lado, participar de la nueva actividad productiva incipiente en la región relacionada al negocio de la vitivinicultura. Por

\footnotetext{
${ }^{14}$ AHA, Departamento General de Irrigación. "Prensa y Memoria”, memoria año 1885.

${ }^{15}$ AHA, Departamento General de Irrigación. "Superintendencia”, año 1885, folio 80.

${ }^{16}$ AGPM, Protocolos, testamentarías y carpetas varias. Año 1854.

${ }^{17}$ AHA, Departamento General de Irrigación. "Prensa y Memoria”, memoria año 1885, pág. 25.
} 
otro lado, continuar con la explotación de alfalfa y ganado a Chile que, a pesar de la retracción del negocio, fue importante en la zona incluso hasta mediados de siglo XX. Otro dato no menor, en 1881 la legislatura promulgó una ley de exención impositiva por el término de 10 años para toda plantación nueva de olivos, viñas y nogales en el territorio provincial ${ }^{18}$, lo que pudo haber fundado el interés por parte de los Ovalle en producir con mayor ímpetu sus terrenos.

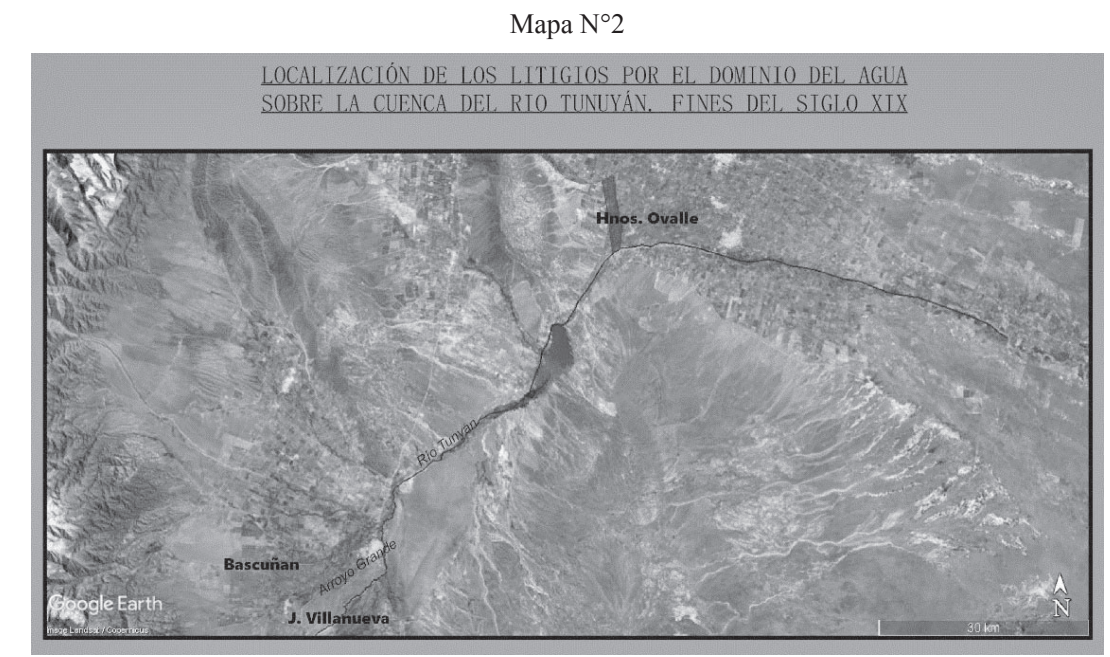

Fuente: Elaboración propia sobre la base de Mapa de la Provincia de Mendoza (1892) y Plano Catastral (1912). Año 2019.19

Así las cosas, en 1885 Pastor Ovalle se presenta ante el Juez de Aguas con el objetivo de solicitar la concesión de riego para 1500 hectáreas. Esto desencadenó un proceso legal entre el gobierno de la provincia y el privado Pastor Ovalle. El litigio llevó al Juez de Aguas de la provincia de Mendoza a negarle el pedido para regar el equivalente a unas 888 cuadras.

El caso de Pastor Ovalle fue uno de los primeros fallos en que la provincia pudo imponer el espíritu de la ley de agua sancionada en 1884. Como se registró en el libro de resoluciones ${ }^{20}$ donde figura el fallo judicial a favor del Gobierno de Mendoza, el superintendente ordenó que se archive y siente precedente en materia de litigios contra la provincia. Además, los fallos de este tipo implicaron la consolidación de una autoridad en lo concerniente al agua y su justicia.

\subsection{El debate de los litigantes}

El principal argumento esgrimido por Ovalle señaló que él poseía una servidumbre de aguas, es decir, un derecho inherente a la tierra que ocupaba y por

\footnotetext{
${ }_{18}$ Jorge Scalvini, Historia de Mendoza” Mendoza: Ed. Spadoni (1965).

${ }^{19}$ Archivo General de la Nación (AGN): Mapas históricos.

${ }^{20}$ AHA, Departamento General de Irrigación, “Superintendencia”, año 1885
} 
la cual el Gobierno de la Provincia era incompetente jurisdiccionalmente en dicho asunto. Con esto se generó una controversia que trascendió lo administrativo y llegó a ser contencioso. Esto implicaba una contienda entre derecho público y privado y el daño de un derecho perfecto. En esta situación fue que logró la intervención de la Cámara Federal.

Por otra parte, el primer argumento que señaló Bermejo es que Ovalle recurrió en un principio al Juez de Aguas para empadronar las tierras y cuando éste le negó el derecho, desconoció a la autoridad administrativa local que la proveyó.

En segundo lugar, Bermejo adujo que el caso en cuestión era de carácter meramente administrativo, con esto lo que sugirió fue la inexistencia de daño al derecho privado, como tampoco lesión alguna a un derecho perfecto y absoluto. Como se mencionó anteriormente, en este punto se jugó también una dimensión federalprovincial frente a una nacional y centralizadora. Lo que señalaba el Procurador fiscal de la provincia de Mendoza fue que Pastor Ovalle debió presentarse "[...] en la forma que prescribe la Ley de Aguas vigente". ${ }^{21}$ En una larga argumentación sobre este punto Bermejo se basó en la jurisprudencia francesa que permitía contextualizar los conflictos del agua en la esfera administrativa pública, sacándolos de lo contencioso.

El tercer argumento de peso que esgrimió fue el del dominio público de las aguas en términos de propiedad estatal, por lo que los individuos tenían una concesión de las aguas que se debían subordinar (en caso de ser necesario) a los intereses colectivos. Para sustentar tal declaración recopiló a los tratadistas franceses y documentos como las ordenanzas de Alcalá, la Recopilación de Indias y Derecho Romano. Sin embargo, fue el Código Civil de 1869, el principal documento que instituyó este sentido de la ley debido a que en él se enumeraron los bienes de dominio público entre los que se encontraban los ríos, sus cauces y las aguas que corrían por los cauces naturales y toda otra agua que tuviese la potencialidad de satisfacer usos de interés general.

El cuarto argumento sostenía que como "[...] hay épocas en que apenas alcanza el caudal" 22 para sostener los cultivos, se tornaría imposible proveer de agua a la extensión de tierra que exigía el demandante. En quinto lugar, Bermejo señaló que fue la Ley de Agua de 1884 la que se constituyó como derecho perfecto para la provincia de Mendoza, por lo que una vez más el énfasis se posicionó sobre las autonomías provinciales y el régimen federal. En cuanto al sexto argumento del letrado, respondió la pretensión de Ovalle de establecer su derecho como una servidumbre de agua. Justamente el Código Civil hacía referencia a que los bienes inmuebles eran inalienables y que no podían constituir servidumbre.

La figura reglamentaria que según Bermejo le correspondía a la situación de conflicto sería el de usufructo legal. Por lo que de esta caracterización derivó el

\footnotetext{
${ }^{21}$ AHA, Departamento General de Irrigación, "Prensa y Memoria", memoria año 1885.

${ }^{22}$ AHA, Departamento General de Irrigación. "Prensa y Memoria”, memoria, 1885, pag.8.
} 
sexto argumento en el que manifestó que, con 20 años de ausencia en la explotación, el usufructo legal ya estaba extinto y con él su derecho a reclamar. Bermejo estableció que, si bien existía un derecho de uso o goce de las aguas, éste se encontraba subordinado a las leyes locales.

Para finalizar, argumentó que la Corte Nacional ya había otorgado a las provincias autonomía en materia de agua en el año 1875, señalando el caso Río de los Valles en la provincia de Salta en el cual sus aguas fueron consideradas bienes públicos. De hecho, como el mismo juez que se ocupaba de la causa Ovalle había participado de ese proceso, Bermejo expresó: “[...] el interesante fallo del Sr. Juez de Sección de esa Provincia, tantas veces citado, formuló la verdadera doctrina constitucional que mereció la confirmación de V.E.". ${ }^{23}$ En dicho fallo se estableció el derecho de uso y goce de las aguas, pero sujeto a las normas de la administración local, además de establecerse la constitucionalidad de tal regulación.

\subsection{La sentencia dictada por el tribunal}

La sentencia resultó favorable para la provincia de Mendoza evidenciando el momento particular de la institucionalidad nacional. Este caso ajustó las interpretaciones sobre el dominio privado o público de las aguas que escurren dentro del territorio provincial, dotando de autoridad a las instituciones y organismos que debían regular esta situación. Hacia el 4 de julio de 1886 el procurador fiscal de la nación Eduardo Costa envió la sentencia al abogado Antonio Bermejo. La nota introductoria a la sentencia da una noción de las principales ideas que se sostuvieron. El fiscal destacó la calidad del escrito con que se refutaron las ideas de Ovalle y reforzó algunas ideas claves. Entre otras, que las aguas de los ríos: "Constituyendo el elemento primero de la vida de la comunidad, la autoridad, los Gobiernos de Provincias entre nosotros pueden en todo tiempo aumentar i restringir su uso sin consideración a derechos anteriores, que nadie los tiene a perpetuidad, tratándose de cuestiones de orden público". ${ }^{24}$

La sentencia dictada por el tribunal repasó en gran parte los fundamentos que desarrolló Bermejo, aludiendo al carácter público de las aguas, por el cual se establecía el derecho de "uso y goce" de las aguas, pero no un derecho perfecto sobre las mismas. Con ello, la sujeción a las autoridades locales y competentes en la materia. Además, dichos derechos establecidos podían ser revocables en función del interés público. Otra idea que desarrolló la sentencia tuvo que ver con la escasez de agua que existía en la provincia por lo cual se prohibía conceder nuevos derechos hasta tanto se cumpliera con la realización de los aforos de los ríos. Finalmente, el fallo manifestó que: "Por estos fundamentos: definitivamente juzgando, se declara no haber lugar a la demanda interpuesta, y se absuelve en consecuencia de ella a la Provincia demandada". ${ }^{25}$

\footnotetext{
${ }^{23}$ AHA, Departamento General de Irrigación. "Prensa y Memoria", memoria, 1885, pág. 46.

${ }^{24}$ AHA, Departamento General de Irrigación. "Superintendencia”,1885, folio 78.

${ }^{25}$ AHA, Departamento General de Irrigación. "Superintendencia", 1885, folio 80.
} 
En definitiva, el fallo expresó que el poder administrativo y de policía sobre las aguas quedaba en manos de las autoridades provinciales. En efecto, quienes definían el interés público de las aguas eran las elites gobernantes dentro del estado. En este sentido, subyace el reforzamiento del poder político sobre las aguas. En otras palabras, el interés (personal y privado) de la elite gobernante se revestía de "interés público". Esta herramienta jurídica permitió un manejo discrecional de las aguas, lo que significa que su utilización habilitó prácticas de apropiación del agua beneficiando a ciertos grupos en detrimento de otros. Por lo dicho, antes que el dominio público de las aguas en forma estricta deberíamos decir que se trata del dominio estatal de las aguas. Esto ha sido documentado por diversos estudios que problematizaron sobre el acceso, control y apropiación de los recursos hídricos por la vía estatal. ${ }^{26}$

\section{Conflictos por el agua entre privados: Los casos de los chilenos Bascuñan y Baltra}

En el presente apartado desarrollaremos dos ejemplos que nos ayudarán a figurar el tipo de argumentos que se desplegaron en los conflictos sobre aguas, los mismos pueden ser observados en la imagen satelital de la Fig. $\mathrm{N}^{\circ} 2$ del apartado anterior. En los siguientes párrafos también se ponen de manifiesto las discusiones sobre el dominio público (estatal) o privado de las aguas.

El iniciador del primer caso fue el ciudadano chileno Juan Manuel Bascuñan pidiendo apelación de lo dispuesto por la inspección el 24 de octubre de 1876 . El juez de la hijuela del Arroyo de la Quebrada había enviado un informe en el que señalaba que: "debe mandar a quienes estén obligados a la colocación de compuertas que se necesiten para medir el agua en las tomas particulares". ${ }^{27}$ Dicha medida fue rechazada por el señor Bascuñan ya que:

[...] se afectan de un modo serio mis derechos en cuanto se manda hacer una divición (sic) de un Arroyo de agua que nace en mi propiedad y en esa divición se me priva de parte de ella que es esa agua cuestión de derecho que ni Ud, es competente para resolver, ni puede sustanciarse sin mi audiencia, con todas las tramitaciones legales. ${ }^{28}$

En el expediente quedaron registrados también los reclamos de los vecinos que usufructuaban el Arroyo de la Quebrada en Tupungato aguas abajo.

\footnotetext{
${ }^{26}$ Elma Montaña, "Las disputas territoriales de una sociedad hidráulica. Conflictos en torno al agua en Mendoza, Argentina" REVIBEC-FLACSO, (2008); Martín, Facundo, Facundo Rojas, y Leticia Saldi. "Domar el agua para gobernar. Concepciones sociopolíticas sobre la naturaleza y la sociedad en contextos de consolidación del Estado provincial mendocino hacia finales del siglo XIX y principios del XX" Anuario del Centro de Estudios Históricos "Prof. Carlos S. A. Segreti", (2010): 159-186.; Escolar, D., Martín, F., Rojas, F., Saldi, L., \& Wagner, L. "Imaginario ambiental mendocino. Sus efectos en las políticas estatales y la producción científica", Historia, politica y gestión ambiental: Perspectivas y debates. Comps. SALOMÓN Alejandra; ZARRILLI, Adrián. Buenos Aires, Imago Mundi, 77-97, 2012.

${ }^{27}$ AHA, Departamento General de Irrigación. “Archivo Pasivo”, expediente 0101_106, folio 3.

${ }^{28}$ AHA, Departamento General de Irrigación. “Archivo Pasivo”, expediente 0101_106, folio 1.
} 
Por lo que se desprende de la lectura de las diez fojas que componen el expediente existieron acusaciones cruzadas entre los vecinos que utilizaban los terrenos localizados aguas abajo y el Sr. Bascuñan, quien alegaba que no había impedido el paso de la cantidad de agua que se había establecido por derecho en el año 1853. Pero que la cantidad de agua que reclamaban era mayor a la que venían utilizando.

Bascuñan responde negativamente a cada una de las actuaciones dictadas por la Inspección. En el expediente la Inspección le manifiestó que podía quedarse con un tercio del agua que circulaba, pero, éste alegaba que no era jurisdicción de ellos juzgar sobre estos temas. En su última intervención documentada Bascuñan declaró: "Pido que habiendo por interpuesto el recurso en tiempo y forma se sirva concedérmelo libremente y mandar elevar los autos al Superior suspendiendo entre tanto todo procedimiento porque es de justicia". ${ }^{29}$ La última novedad en torno al expediente es del 24 de octubre de 1876 donde Segura señaló "No siendo apelable la resolución de pena q ( $\mathrm{sic}$ ) del corriente a que esta parte se refiere no ha lugar a la apelación". ${ }^{30}$

Los iniciadores del segundo caso seleccionado fueron Jorge Villanueva y Pedro Arroyo, ambos sindicados como representantes de la oligarquía mendocina. El expediente fue presentado el 11 de mayo de 1877, y solicitaba la reposición del agua que había bloqueado un ciudadano chileno de apellido Baltra. El conflicto es referido en el canal Vista Flores, en una zona donde 3 años después será fundado el casco urbano del actual departamento de Tunuyán, conocida en aquel tiempo como "El Totoral"31 y que estaba bajo jurisdicción del departamento de San Carlos.

En este caso los dos solicitantes hacen referencia a un derecho que venían usufructuando hace 16 años de las aguas que procedían del terreno del señor Baltra, quien lo había comprado recientemente a Benjamín Sánchez. Los interesados fundamentaron su pedido en las leyes de aguas de 1871 y 1872 que autorizaban la utilización de las aguas previa su declaración. El señor Baltra dejó en claro desde el comienzo de su descargo que la jurisdicción para tratar sobre el asunto en cuestión era la justicia civil. Una vez que fue recibida la denuncia el subdelegado de aguas de San Carlos informó que: "[...] tenía tapado el agua con que riegan los Sres. Villanueva i Arroyo, a causa de los trabajos que ha hecho el Sr. Baltra en el Molino que está construyendo". ${ }^{32}$ En lo que se refiere al caso el Inspector ordenó que "[...] suspenda

\footnotetext{
${ }^{29}$ AHA, Departamento General de Irrigación. “Archivo Pasivo”, expediente 0101_106, folio 8.

${ }^{30}$ AHA, Departamento General de Irrigación. “Archivo Pasivo”, expediente 0101_106, folio 8.

${ }^{31}$ Es probable que Jorge Villanueva fuese familiar de Elías Villanueva, quien ejerció como gobernador de Mendoza en tres oportunidades, una de ellas interinamente un año antes del conflicto bajo estudio en 1876 y otra un año después de comenzado el conflicto en 1878. Además, es bajo el gobierno de Elías Villanueva que se crea el departamento de Tunuyán en noviembre de 1880 (Municipalidad de Tunuyán, 2019). Según el historiador Santos Martinez en Historia de Mendoza (1979: 321) La actual ciudad cabecera del departamento de Tunuyán se encuentran en los terrenos donde el capitán español Don Juan Amaro del Campo fundara la estancia de "Tolol" o "El Totoral".

${ }^{32}$ AHA, Departamento General de Irrigación. “Archivo Pasivo”, expediente 0101_114, folio 2.
} 
los trabajos que tiene iniciados y que impiden el curso livre del agua". ${ }^{33}$ A lo que Baltra respondió pidiendo la revocatoria de lo dispuesto por el Inspector.

En el expediente queda en evidencia lo difuso que eran las jurisdicciones y competencias en esta etapa de regulación del agua, sobre todo para quienes eran sancionados por la Inspección. Por lo que se desprende de los dos casos que hemos analizado parecía existir una colusión entre la ley de aguas de 1871-72 mencionada por los demandantes y el Código Civil. Tal es así que en la respuesta final del Inspector Segura puede leerse:

Mandando reponer de las aguas de que gozaban los Sres. Arroyo y Villanueva es meramente administrativo [...] dejando en derecho a salvo a los peticionario para que envíen donde corresponda para hacer variar el estado de cosas mantenidos por esta Inspección. ${ }^{34}$

Lo que sugiere esta última cita es la relativa debilidad que aún tenían las instituciones del agua para administrar el recurso. Sobre todo, si se compara con las medidas de la etapa posterior a la sanción de la ley de aguas que tienen un carácter mucho más categórico en sus sentencias y de la cual el caso Ovalle puede considerarse un hito.

En el caso particular de estos dos expedientes, la constante remisión a la jurisdicción de los conflictos intentaba jaquear la autoridad de Irrigación. Y esto en un contexto de consolidación nacional era complejo ya que ponía a prueba los mecanismos judiciales e institucionales del federalismo. Es por ello también que el caso Ovalle parece cobrar relevancia, según Bermejo: "En mi concepto la Suprema Corte Nacional carece de jurisdiccion para reveer ó reformar las resoluciones de los Gobiernos de Provincia". ${ }^{35}$ De esta manera quedan reflejadas las tensiones que venimos advirtiendo, pero además a lo largo de todo el documento se evidencian connotaciones relativas al federalismo y las autonomías provinciales. Vale recordar que, estas instancias se inscriben en pleno proceso de consolidación del Estado Nación, por lo que los conflictos de este tipo reacomodaron las situaciones judiciales e institucionales entre la nación y las provincias.

\section{La naciente burguesía chilena y sus estrategias de inversión: el interés de los Ovalle en los territorios irrigados por el rio Tunuyán}

Su nombre era Pastor Ovalle Errázuriz y era hijo en primeras nupcias de Ramón Ovalle Vivar (1774-1851) y Francisca Errázuriz, ${ }^{36}$ ambos de familias

\footnotetext{
${ }^{33}$ AHA, Departamento General de Irrigación. “Archivo Pasivo”, expediente 0101_114, folio 2.

${ }^{34}$ AHA, Departamento General de Irrigación. “Archivo Pasivo”, expediente 0101_114, folio 5.

${ }^{35}$ AHA, Departamento General de Irrigación. "Prensa y Memoria", memoria año 1885, pág. 8.

36 “...la familia Errázuriz ha sido definida como una dinastía parlamentaria” Vicuña, Manuel. La belle époque chilena: alta sociedad y mujeres de elite en el cambio de siglo. Santiago de Chile: Editorial Sudamericana, 2001: 25 .
} 
pertenecientes a la aristocracia colonial de Chile. ${ }^{37}$ En su prosapia se encuentran duques, coroneles de la etapa de la conquista, presidentes y personas influyentes de la política. No obstante, su conexión con las familias de elite chilenas, el patrimonio de los Ovalle era exiguo. Fue su padre, Ramón, quien devolvió a la familia a las altas esferas durante el auge de la extracción y exportación mineral. Nazer Ahumada (2000) coloca a Ramón Ovalle en un nuevo grupo empresarial chileno que hizo fortuna rápidamente y que estaba dispuesto a diversificar, invertir y modernizar al más puro estilo capitalista. Se diferenciaba de la tradicional élite mercantil-terrateniente caracterizada por su aversión al riesgo y la modernización pero que sostenía el poder político. Ramón Ovalle llegó a ser electo diputado en 1825 por la ciudad de La Ligua, una característica poco frecuente en este nuevo grupo empresarial. Sin dudas, su apellido y el de su esposa hicieron más fácil esta transición que luego continuaría uno de sus hijos, Matías.

Castillo Fernández (2014) menciona que Pastor con su hermano Matías Ovalle $^{38}$ montaron una empresa con la cual se encargaron de urbanizar y administrar una población cerca de Santiago de Chile hacia 1870. La llamada población Ovalle (conocidas como El Arenal o El Carmen) fue obra de ellos. Sin dudas la relevancia de esta obra descansaba en la influencia de Matías Ovalle como Intendente de Santiago de Chile, (además de haber sido ministro y diputado) para traccionar los poderes del estado en pos del proyecto inmobiliario. Castillo Fernández (2014) nos da una buena idea del negocio de los hermanos Ovalle al señalar que alquilaban las tierras a las Monjas del Carmen de San Rafael y las retenían hasta que el sitio daba la ganancia normal más la renta. Hacia 1885 esta vez mediante la compra de una quinta cercana a la anterior, comenzaron una nueva urbanización que extendería la población (y el negocio).

Se sabe también, por intermedio de su hermano (técnicamente medio hermano), que sus intereses y por tanto el mundo social en que se movía estaban relacionados a la industria y la agricultura. Matías, había integrado la Comisión permanente de hacienda e industria desde 1852 hasta 1861, había colaborado en la fundación de la Sociedad Nacional de Agricultura y dirigido la Exposición Nacional de Santiago. Además, participó en el negocio del alumbrado público en Santiago y fomentó la minería en Maipo y Coquimbo. ${ }^{39} \mathrm{Al}$ señalar su prosapia y las actividades a las que se dedicaba Pastor Ovalle y su hermano, se hace referencia a un tiempo y un contexto social, pero también a una clase social que actuaba bajo las tendencias y limitantes que su época le imponía. Por ello, podemos suponer fácilmente las tensiones a que se veían sujetos siendo hijos de la aristocracia chilena pero también de la nueva burguesía con quien, por las noticias que nos han llegado de ambos, compartían intereses.

\footnotetext{
${ }^{37}$ Ambos apellidos son citados por el genealogista e historiador chileno Luis Thayer Ojeda en su libro "Familias Chilenas" dedicado a exaltar la prosapia de algunas de las familias más "renombradas" de Chile. (Thayer Ojeda, 1906)

${ }^{38}$ Ramón Ovalle contrajo matrimonio por segunda vez con su cuñada Mercedes Errázuriz, Matías Ovalle es uno de los cuatro hijos de esta segunda pareja.

${ }^{39}$ Fuente: Biblioteca del Congreso Nacional de Chile, 2019
} 
En el mencionado trabajo de Nazer Ahumada (2000) dedicado a describir las elites empresariales chilenas del siglo XIX se señala la vocación modernizadora y diversificadora que tuvieron estos nuevos grupos empresariales en el cual podemos incluir a Pastor y Matías. Aunque existían diferencias sustanciales entre los empresarios nacionales y los extranjeros. Mientras los extranjeros diversificaron en los rubros financieros, en compañías de seguro, bancos, ferrocarriles, actividades de servicios y el control del negocio de importación y exportación. Los nacionales se diversificaron en otros rubros, por ejemplo, en agricultura donde las inversiones y modernización fueron considerables. La hacienda tradicional chilena dio paso a la modernización de sus canales de riego, herramientas y maquinarias, además de la incorporación del ferrocarril y modernos cultivos, alentados por la exportación de harina y trigo a diferentes países.

También se inicia una etapa floreciente para la vitivinicultura desde mediados del siglo XIX: "El ser dueño de una viña era un título honorífico, que daba derecho a figurar en los grandes torneos de las exposiciones mundiales". ${ }^{40}$ Aunque, el sólo hecho de tener una estancia ya otorgaba cierto prestigio social que se orientaba a imitar algunos de los rasgos de la aristocracia chilena. Otro de los rubros hacia donde se diversificaba fue el inmobiliario. El cambio de fisonomía de las ciudades (sobre todo Valparaíso y Santiago) durante este período respondió en gran parte a las inversiones de grupos provenientes de la minería. Por último, como ya se dijo, muy pocos de este nuevo grupo de empresarios lograron una participación política efectiva. Los grupos de raíces aristocrática lograron mantener su cohesión y unidad frente al poder de estos nuevos empresarios que irían, no obstante, ampliado su participación política hacia finales de siglo.

Pastor y Matías Ovalle respondían prototípicamente a ciertas actitudes propias de la clase burguesa a la que pertenecían, se diversificaron en los rubros agrícola, minero, inmobiliario y político. Su participación política fue posible por su linaje en una etapa particularmente complicada para la clase empresarial a la que pertenecían. Sin dudas, su doble pertenencia de clase fue combinada para usufructuar lo mejor de ambas en sus emprendimientos empresariales. Y esta combinación de mundos se vio también manifiesta en la forma de hacer negocios. Por ejemplo, mientras el nuevo empresariado tendió a dejar de lado la administración de carácter familiar por un sistema más profesionalizado, en contraste las elites tradicionales y los Ovalle tendían a realizar la ampliación de sus negocios mediante una estructura de administración familiar. Vicuña (2001) señala que la familia fue primordial en la esfera económica y política. Por un lado, porque de esa manera se podía lograr cierta diversificación de las actividades y conformar una red en varias esferas de la producción. Así, la familia de clase alta organizada como red económica diversificada "[...] incidió de manera fundamental en la integración sectorial y territorial de la economía chilena". ${ }^{41}$ Por otro

\footnotetext{
${ }^{40}$ Nazer Ahumada, Ricardo. "El surgimiento de una nueva elite empresarial en Chile: 1830-80", Minoranze e culture imprenditoriali. Cile e Italia secoli $(X I X-X X)$. Franco Bonelli y Maria Rosaria Stabili, 59-84. Roma: Carocci, 2000:75.

${ }^{41}$ Manuel Vicuña, La belle époque chilena: alta sociedad y mujeres de elite en el cambio de siglo. Santiago de Chile: Editorial Sudamericana, 2001:30
} 
lado, la institución de la familia y el juego político en torno a lo parental fue un legado colonial que se reforzó en las siguientes etapas históricas, por lo cual, la concentración del poder en manos de la pequeña élite urbana santiaguina fue un proceso histórico de largo aliento. Diversos factores históricos reforzaron esta situación, aunque lo que nos interesa es la forma de actuar de la elite chilena. En nuestro caso era relativamente más sencillo dado que nuestros protagonistas portaban apellidos de renombre y descendían de forma directa de esa élite aristocrática. Pero, además, porque los mecanismos por los que se obtenía el prestigio y el control de las actividades estatales eran mediante la práctica política. Es probable que el recuerdo de las privaciones pasadas y las presiones familiares y sociales, esperables para los hijos de su casta, hayan orientado a una estrategia de sostenerse en la política como principal capital y optaran por una estrategia empresarial de tipo familiar para sustentar el patrimonio y los recursos.

En términos generales la burguesía chilena también mantenía sus negocios en los territorios localizados al este de la Cordillera de Los Andes. Se destaca en un principio el comercio de esclavos-indígenas como mano de obra, mientras que a partir del siglo XVII los intercambios agrícolas y ganaderos fueron relevantes para el desarrollo de la economía de Cuyo. ${ }^{42}$

Como se observa en la Fig. $\mathrm{N}^{\circ} 3$ los casos analizados se desarrollan en la cuenca del río Tunuyán, en la Región de los Andes Centrales. Las aguas del Tunuyán irrigan los territorios del Valle de Uco (actuales departamentos de Tupungato, Tunuyán y San Carlos) desde el oeste para luego surcar la vasta llanura árida hasta los territorios del este provincial (actuales departamentos de Rivadavia y La Paz) inclinándose, en el último tramo, hacia el sur perdiéndose sus aguas en el río Desaguadero.

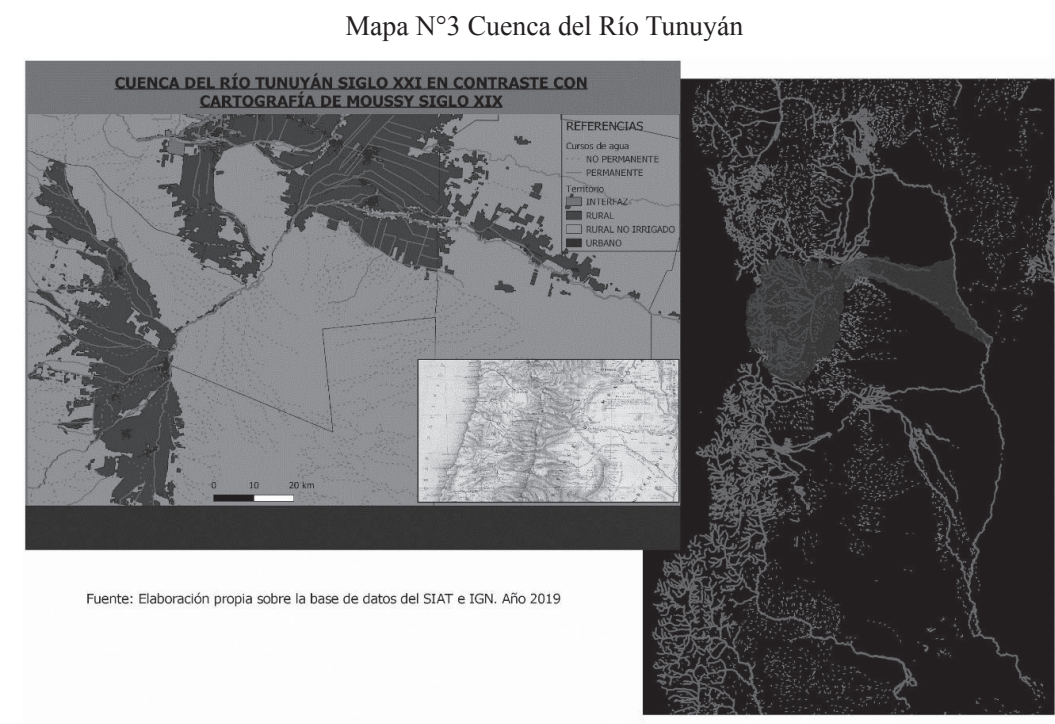

\footnotetext{
${ }^{42}$ Pablo Lacoste, Mendoza. Historia y perspectivas. Aportes para el estudio de una ciudad fundada en 1561. Diario Uno, Mendoza.
} 
Moussy ${ }^{43}$ dejó asentado en sus escritos que los suelos de la Travesía del Tunuyán eran los de tipo planicie-arenosos, cubiertos de bosques de mimosa espinosa, parcialmente salinos y sin agua dulce. Estos sedimentos areno-arcillosos son transportados, desde el oeste y el sur, por los ríos secos que surcan la meseta durante las lluvias torrenciales de verano. Los suelos fértiles sólo se encontraban cerca de los ríos lo que es propio de las regiones áridas y por ello las disputas que se generaban en torno a la apropiación y manejo del agua. Considerando las tendencias productivas de la época, los terrenos eran trabajados para la producción de alfalfa con vistas al engorde y cría de ganado.

D. Eusebio Videla decía sobre el Valle de Uco, en 1801: “[...] que se extiende cincuenta leguas hacia el sur hasta la tierra de los indios y otras tantas al oriente. En cuyos pastosos campos abundantes arroyos se hallan establecidas las principales poblaciones de estancias". ${ }^{44}$ Richard Jorba (1998) también señala la constante presión que existía para la valorización de las tierras, desde 1800 en adelante. Estas presiones iban marcando diferencias sustanciales en el paisaje que fue transformándose de pequeños oasis separados espacialmente a conformar un gran oasis integrado.

\section{Mapa $\mathrm{N}^{\circ} 4$}

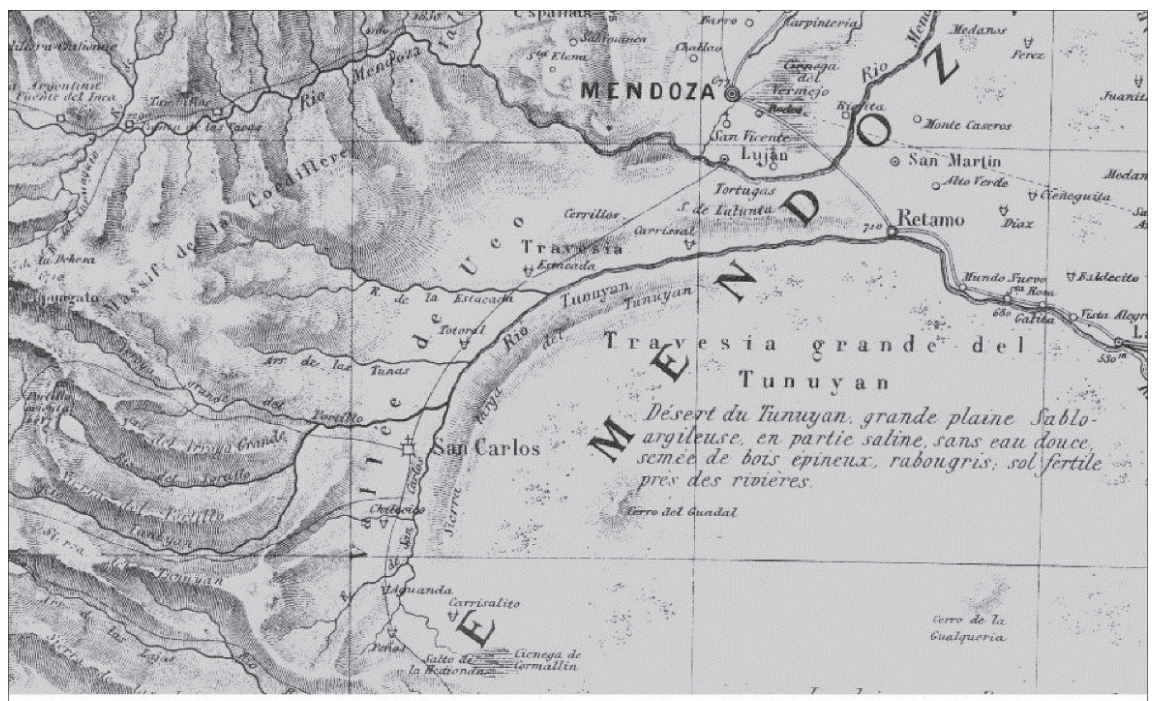

CUENCA DEL TUNUYÁN EN BASE A "CARTA DE LA PROVINCIA DE MENDOZA DE LA ARAUCANÍA DE LA GRAN PARTE DE CHILE, ELABORADA POR EL DR. V. MARTÍN MOUSSY AÑO $1865^{\prime \prime}$

En el Mapa N4, versa: “Désert du Tunuyán. Grande plaine sablo argileuse, en partie saline sans eau douce semie de bois epineux rabougris sol fertile pres des rivieres". ${ }^{45}$

\footnotetext{
${ }^{43}$ Víctor De Moussy, Description géographique et statistique de la Conféderation Argentine 181-1869, 1869

${ }^{44}$ Jorge Scalvini, Historia de Mendoza, Mendoza: Ed. Spadoni (1965): 88.
}

45 Archivo General de la Nación (AGN): Mapas históricos. 
Por otra parte, a raíz del censo de 1869 realizado durante la presidencia de Sarmiento se tiene conocimiento de que el $83 \%$ de la tierra cultivada en la provincia correspondían a alfalfa, ya que el ganado que se exportaba a Chile era engordado en tierras mendocinas. Mientras que el maíz y el trigo ocupaban el 7\%, a diferencia de la vid que estaba cultivada en un $4 \%$ de la tierra y la producción de frutales en un 3\%. ${ }^{46}$

Otro dato de importancia para comprender el contexto social de la época es que sobre el total de los habitantes censables ${ }^{47}$, aproximadamente el $10 \%$ de la población era extranjera, mayoritariamente proveniente de la región trasandina. Lo anteriormente dicho adquiere importancia si tenemos en cuenta el contexto de auge en el que se encontraba la cuenca del río Tunuyán y los vínculos existentes entre las comunidades de ambos territorios señalados, sobre todo como consecuencia de las actividades comerciales. Esto también se veía reflejado en la composición de las élites locales y chilenas que además de las alianzas comerciales compartían lazos de parentesco en muchos casos.

Hasta finales del siglo XIX el cultivo de la alfalfa en Mendoza estuvo vinculado a la producción ganadera siendo Chile el mayor comprador de semoventes. ${ }^{48}$ A pesar de todo lo señalado debe comprenderse que el sistema ganadero vigente en la zona de Cuyo desde mediados de siglo XIX gozó de gran importancia incluso hasta mediados del siglo XX. Por ejemplo, para el año 1884 se exportaron 45.741 cabezas de ganado a Chile ${ }^{49}$ y aún en un marcado retroceso para 1887 se exportaron unas 29.166 cabezas. Uno de los cambios significativos fue la reorientación de las familias que componían la elite gobernante. Este grupo de carácter más modernizante se orientó a la vitivinicultura y tenía como banderas, la consolidación institucional del país y la difusión del ferrocarril como elemento de integración. Los antiguos comerciantes integrados comercial y familiarmente a la elite chilena si bien invirtieron en vitivinicultura no dejaron de sostener el comercio ganadero con Chile. Lo que a juicio de Richard Jorba ${ }^{50}$ los llevó a ceder espacios en la esfera pública.

Luego de la recesión de 1873 entró en crisis el negocio ganadero, sumado a esto se produjo la consolidación del poder nacional y la llegada del tendido ferroviario a la provincia. Estos cambios dieron como principal resultado la interiorización de Mendoza, es decir, la subordinación de la provincia al Estado-Nación conducido desde Buenos Aires. Y por ende el desacople de la integración Mendoza-Valparaíso.

\footnotetext{
${ }^{46}$ Pedro Martínez, S. Historia de Mendoza (Vol. 7). Plus Ultra. 1979.

${ }^{47}$ El primer censo argentino se realizó bajo la presidencia de Domingo Faustino Sarmiento, en septiembre de 1869 , ese mismo año se publica la obra de Víctor de Moussy.

${ }^{48}$ Pedro Martínez, S, 1979.

${ }^{49}$ Rodolfo Richard Jorba, Poder, Economía y Espacio en Mendoza 1850-1900. Mendoza: Editorial de la Facultad de Filosofía y Letras de la Universidad Nacional de Cuyo, 1998.

${ }^{50}$ Miguel Marzo y Osvaldo Inchauspe, Geografia de Mendoza, 1967.
} 


\section{Conclusiones}

A partir del análisis documental y cartográfico realizado se pudieron establecer algunas conexiones entre diversos procesos sociales, históricos y territoriales. Los litigios estudiados se desarrollaron en un momento de consolidación del estado nacional argentino. A su vez se produjo un fortalecimiento de las jurisdicciones provinciales con marcado acento federalista. Esto se vio reflejado en una creciente dificultad de la actividad institucional. En nuestro caso el agua, como factor productivo necesario en tierras áridas fue producto de múltiples disputas. La consolidación de una autoridad del agua y su institucionalización permitieron una gestión más ágil y discrecional del recurso por parte de la elite gobernante en el poder.

La referencia a los orígenes sociales de los Ovalle nos ha servido para demostrar la configuración de un sujeto histórico sometido a fuerzas y dinámicas sociales más amplias. Y a partir de ello ver el comportamiento común de las familias de élite chilenas y sus orientaciones productivas. Es decir, nos ha permitido trascender los casos para enmarcarlos en un proceso mayor.

A partir de los argumentos de Bermejo y el fallo judicial pudimos repasar las ideas del dominio público de las aguas y la competencia de las autoridades locales en materia de su administración y distribución. Con lo cual el poder administrativo y de policía sobre las aguas quedaba, al menos para la Corte Federal, en manos de las provincias. Esto fue una herramienta importante para la elite local, en tanto le permitió un mayor manejo y discrecionalidad para reorientar las actividades productivas. Por lo cual, debe enfatizarse en el dominio público, pero sobre todo estatal de las aguas.

Tanto las nuevas adecuaciones institucionales como jurídicas se inscriben dentro de dinámicas en que colisionan estrategias productivas de las familias chilenas capitalizadas como de las elites locales que buscaban la interiorización de la provincia. Por tanto, el trasfondo de los casos presentados coincide con un momento de desacople de la economía mendocina del intercambio predominante con Chile. Los años subsiguientes reforzarán dicha tendencia marcando una reorientación productiva de la provincia hacia la vitivinicultura.

\section{Bibliografía}

\section{Fuentes primarias}

\section{Fuentes de archivo}

Archivo Histórico del Agua (AHA) del Departamento General de Irrigación. Prensa y memoria, superintendencia y archivo pasivo. 
El dominio público y privado de las aguas del río Tunuyán: Litigios a finales del siglo XIX en...

Archivo General de la Provincia de Mendoza (AGPM). Protocolos, testamentarías y carpetas varias.

Archivo General de la Nación (AGN): Mapas históricos.

\section{Fuentes secundarias}

\section{Libros}

Castillo Fernández, Simón. El Río Mapocho y sus riberas. Espacio público e intervención urbana en Santiago de Chile (1885-1918). Santiago de Chile: Ediciones Universidad Alberto Hurtado, 2014.

De Moussy, Victor M. Atlas de la Confederation Argentine, Descripción geográfica y estadística de la Confederación Argentina. Academia Nacional de la Historia. Fundación Banco de la Provincia de Buenos Aires. Buenos Aires Tomo I 556 pp, Tomo II 650pp, Tomo III 792pp, 2005.

De Moussy, Victor M. Description géographique et statistique de la Conféderation Argentine 181-1869, 1869.

Elías, Norbert. Mozart, sociología de un genio. Barcelona: Cultura Libre, 1991.

Lacoste, P. Mendoza. Historia y perspectivas. Aportes para el estudio de una ciudad fundada en 1561. Diario Uno, Mendoza, 1997.

Martín, Facundo. Las transformaciones recientes en la agricultura de oasis en Mendoza, Argentina. Una aproximación al caso de la reestructuración vitivinícola desde la economía política de la agricultura. MS thesis. Buenos Aires: FLACSO. Sede Académica Argentina, 2009.

Martínez Santos, Pedro. Historia de Mendoza (Vol. 7). Ed. Plus Ultra, 1979.

Marzo, Miguel y Osvaldo Inchauspe. Geografía de Mendoza.1967.

Ponte, J. Mendoza, aquella ciudad de barro. Historia de una ciudad andina desde el siglo XVI hasta nuestros días. Talleres gráficos de la Imprenta Municipal de la ciudad de Mendoza. Argentina, 2010.

Richard Jorba, Rodolfo. Poder, Economía y Espacio en Mendoza 1850-1900. Mendoza: Ed. de la Facultad de Filosofía y Letras de la Universidad Nacional de Cuyo, 1998.

Scalvini, Jorge Historia de Mendoza. Mendoza: Ed. Spadoni, 1965. 
Thayer Ojeda, Luis. Familias chilenas. Santidago de Chile: Guillermo E. Miranda Editor, 1906.

Thompson, Edward Palmer La formación de la clase obrera en Inglaterra. Barcelona Ed. Crítica, 1989

Vicuña, Manuel. La belle époque chilena : alta sociedad y mujeres de elite en el cambio de siglo. Santiago de Chile: Ed. Sudamericana, 2001.

\section{Capítulos de libros}

Escolar, D., Martín, F., Rojas, F., Saldi, L., \& Wagner, L. "Imaginario ambiental mendocino. Sus efectos en las políticas estatales y la producción científica", Historia, politica y gestión ambiental: Perspectivas y debates. Comps. SALOMÓN Alejandra; ZARRILLI, Adrián. Buenos Aires, Imago Mundi, 77-97, 2012.

Martín, Facundo, Facundo Rojas, y Leticia Saldi. "Domar el agua para gobernar. Concepciones socio-políticas sobre la naturaleza y la sociedad en contextos de consolidación del Estado provincial mendocino hacia finales del siglo XIX y principios del XX" Anuario del Centro de Estudios Históricos "Prof. Carlos S. A. Segreti”, 2010.

Nazer Ahumada, Ricardo. "El surgimiento de una nueva elite empresarial en Chile: 1830-80", Minoranze e culture imprenditoriali. Cile e Italia secoli (XIX-XX). Franco Bonelli y Maria Rosaria Stabili, 59-84. Roma: Carocci, 2000.

\section{Artículos de revistas}

Barrera, Rosier O. "Hidrología del río Tunuyán". Boletín de Estudios Geográficos, 36 (1962).

Chiaramonte, José Carlos. "La cuestión regional en el proceso de gestación del Estado nacional argentino. Algunos problemas de interpretación." Estado y sociedad en el pensamiento nacional (1983): 159-20

Ivars, Jorge Daniel. "Mercados mundiales y racionalización del uso del agua en Mendoza (Argentina)." Ánfora 22.39 (2015): 71-97.

Montaña, Elma. "Identidad regional y construcción del territorio en Mendoza (Argentina): memorias y olvidos estratégicos." Bulletin de l'Institut français d'études andines 36 (2) (2007): 277-297.

Ots, María José, Cahiza, Pablo y Gascon, Margarita. "Articulaciones del corredor trasandino meridionaL: El río Tunuyán en el Valle de Uco Mendoza, Argentina”. Revista de Historia Americana y Argentina, 50, № 1, (2015): 81-105. 
El dominio público y privado de las aguas del río Tunuyán: Litigios a finales del siglo XIX en...

Ponte, Jorge. "Historia del regadío: las acequias de Mendoza, Argentina". Scripta Nova, X, núm. 218 (2006): 18-35.

Prieto, María y Abraham, Elena. "Caminos y comercio como factores de cambio ambiental en las planicies áridas de Mendoza (Argentina) entre los siglos XVII y XIX" Theomai, 2 (2000): 47-62.

\section{Publicaciones en internet}

http://www.ign.gob.ar/cartografia-historica/ (2019).

http://datos.minem.gob.ar/dataset/mapas-historicos/ (2019).

https://www.mendoza-conicet.gob.ar/ladyot/catalogo/cdandes/pa412.htm (2019).

http://www.historiademendoza.com.ar/ (2019). 